\title{
Fatores determinantes das diferenças salariais entre as ocupações da contabilidade
}

\author{
MARA VOGT ${ }^{1}$ \\ EDMERY TAVARES BARBOSA ${ }^{2}$ \\ MARCIA ZANIEVICZ DA SILVA ${ }^{1}$ \\ ARNO PAULO SCHMITZ ${ }^{3}$ \\ ${ }^{1}$ Universidade Regional de Blumenau (FURB) / Departamento de Contabilidade, BLUMENAU - SC, Brasil \\ ${ }^{2}$ Universidade Federal da Paraíba (UfPB) / Departamento de Finanças e Contabilidade, JoÃo Pessoa - PB, BrasiL \\ ${ }^{3}$ Universidade Federal do Paraná (UfPR) /Setor de Educação Profissional e TeCnológica, Curitiba - PR, Brasil
}

\section{Resumo}

Com o objetivo de descrever os fatores determinantes das diferenças salariais entre os profissionais da contabilidade no Brasil, foi realizada uma pesquisa descritiva, documental e quantitativa dos profissionais com os cargos de Auditor, Contador e Auxiliar Contábil (segundo o Código Brasileiro de Ocupações- $\mathrm{CBO}$ ). Os resultados a partir do uso de regressões com variáveis binárias e, no contexto das variáveis analisadas (para os anos entre 2009/2015) são: a) os baixos salários são significativos entre as profissionais do gênero feminino que se declararam negras ou mulatas, com ensino médio, alguma deficiência e que estão no primeiro emprego ou contratadas por tempo pré-estabelecido; b) o indivíduo que tende a receber um salário mais elevado é o ocupante do cargo de Contador, homem, branco, entre 30 e 39 anos de idade, com ensino superior completo e não é deficiente. Adicionalmente, este indivíduo atua, pelo menos, em um segundo emprego, trabalha em uma empresa com até quatro funcionários e é residente da região Sudeste do Brasil.

Palavras-chave: Diferença salarial. Fatores determinantes. Ocupações contábeis. Teoria do capital humano. Teoria da segmentação.

\section{The Wage Gap in Accounting Positions}

\section{Abstract}

This research aimed to describe the wage differences among accounting occupations in Brazil. A descriptive, documental, and quantitative research was carried out with auditors, accountants, and accounting assistants (occupations defined by the Código Brasileiro de Ocupações CBO). The study used regressions with binary variables analyzing data from 2009 to 2015. The results showed that low wages are significant among female black or mulatto workers; workers who completed high school and do not have a degree; with a disability; and in their first job or hired under a fixed-term contract. Also, the study observed that individuals who receive a higher wage are accountants, caucasian male, between 30 and 39 years old, holding a degree, and not disabled. The individuals with higher wages have work experience (they are at least in their second work contract), are employed in a company with up to four employees, and are residents of the Southeast region of Brazil.

Keywords: Wage gap. Determinant factors. Accounting occupations. The human capital theory. The segmentation theory.

\section{Determinantes de las diferencias salariales entre los puestos contables}

\section{Resumen}

Para describir los determinantes de las diferencias salariales entre los profesionales de contabilidad en Brasil, se realizó una encuesta descriptiva, documental y cuantitativa de profesionales con los cargos de auditor, contador y asistente de contabilidad (de acuerdo con el Código Brasileiro de Ocupações - CBO). Los resultados del uso de regresiones con variables binarias y, en el contexto de las variables analizadas (para los años de 2009 a 2015) son: a) los bajos salarios son significativos entre las profesionales que se declararon negras o mulatas, con educación secundaria, alguna discapacidad y que están en su primer trabajo o contratadas por un tiempo preestablecido; b) la persona que tiende a recibir un salario más alto es quien tiene el cargo de contador, hombre, blanco, entre 30 y 39 años de edad, con educación superior completa y sin discapacidad. Además, esta persona trabaja, al menos, en un segundo empleo, trabaja en una empresa con hasta cuatro empleados y es residente de la región Sudeste de Brasil.

Palabras clave: Diferencia salarial. Factores determinantes. Puestos contables. Teoría del capital humano. Teoría de la segmentación. 


\section{INTRODUÇÃO}

No mundo contemporâneo, a variação salarial é uma característica do mercado de trabalho. Os determinantes dessa variação são fatores explícitos como habilidades, conhecimento, escolaridade e características implícitas/discriminatórias, por exemplo devido ao gênero, raça e religião. A sociedade moderna, mesmo nos países desenvolvidos, não suprimiu a remuneração diferenciada (salário, bônus e outros) que geralmente privilegia alguns indivíduos, especialmente as diferenças relacionadas com questões extrínsecas às necessidades de uma ocupação.

Ocorre que, para erradicar as práticas de discriminação salarial, é necessário que se dissemine sua ocorrência (todas as esferas do governo, lideranças comunitárias, educadores e pesquisadores, dentre outros elementos). Além disso, deve-se entender como tais práticas ocorrem empiricamente, nos diferentes níveis de desenvolvimento, e na análise de determinadas esferas. Exemplos dessas esferas são: econômica, social e cultural (as quais devem ser avaliadas pelo país e pelas áreas geográficas), característica empresarial (tamanho e setor da atividade econômica) e peculiaridades de certas ocupações.

Há desigualdade salarial em diversas áreas, e isso tem atraído a atenção de pesquisadores a partir de diferentes abordagens teóricas. Entre as contribuições para a compreensão do tema, têm-se a teoria do capital humano e a teoria da segmentação. A teoria do capital humano, cujo precursor é Mincer (1958), revela a existência de uma relação entre investimentos em educação, formação da população e distribuição de renda. Posteriormente, Becker (1964) verificou empiricamente que a formação e a melhoria da produção são as consequências dos investimentos em educação. Em outras palavras, a educação torna as pessoas mais produtivas, aumentando seus salários, o que afeta diretamente o crescimento econômico. Desse modo, a renda dos trabalhadores tende a crescer de acordo com o capital humano acumulado.

Por outro lado, a teoria da segmentação postula que os trabalhadores podem ter salários diferentes, mesmo que sejam igualmente produtivos. Portanto, a segmentação ocorre quando os trabalhadores têm características produtivas semelhantes, mas seus salários diferem. Assim, a desigualdade salarial pode ser derivada da diferença entre regiões geográficas, preconceitos quanto à raça, gênero e experiência no trabalho, entre outras questões (SOUZA, 1978).

Tanto a teoria do capital humano quanto a da segmentação apresentam fatores relacionados à empregabilidade e remuneração (soma do salário, bônus etc.) dos trabalhadores, de acordo com o comportamento do mercado de trabalho. Ambas as teorias buscam explicar a diferença salarial no mercado de trabalho. No entanto, a teoria do capital humano está relacionada ao conhecimento e à formação, enquanto a teoria da segmentação é inspirada em outras questões ou fatores ligados à localização ou características intrínsecas (raça, religião, gênero, dentre outros).

Com foco nos aspectos supracitados, várias pesquisas na área contábil têm centrado atenção para a desigualdade salarial, o desenvolvimento de carreira a longo prazo e as barreiras à ocupação de cargos de prestígio na contabilidade (SILVA, DAL MAGRO e SILVA, 2016; HAYNES, 2017).

No Brasil, onde a diversidade cultural coexiste com o "mito da democracia racial", a má distribuição de renda tem um impacto significativo no desenvolvimento socioeconômico e regional. Além disso, diferentes níveis de apropriação da educação, saúde e outros serviços públicos implicam no acesso a oportunidades de emprego. $O$ contexto regional também é identificado como um dos fatores que podem determinar a desigualdade salarial (FIELDS e YOO, 2000; SILVA, DAL MAGRO e SILVA, 2016). No entanto, poucas pesquisas centram atenção à temática que relaciona o perfil dos cargos contábeis com e seu salário, limitação a qual esta pesquisa se propõe a investigar.

Nesse sentido e em consonância com estudos focados na análise de características discriminatórias em cenários específicos, formula-se a seguinte questão de pesquisa: quais fatores explicam a diferença salarial (considere soma do salário, bônus etc. como remuneração) entre cargos contábeis? Em decorrência da questão de pesquisa, tem-se como objetivo descrever os fatores determinantes das diferenças salariais entre os profissionais da contabilidade no Brasil. Os fatores pessoais investigados são: gênero, raça, idade, escolaridade, tipos de deficiência e tempo de trabalho (experiência). Por sua vez, os fatores contextuais são: tamanho e região geográfica de localização da empresa.

As motivações para uma pesquisa especificamente no contexto brasileiro são as seguintes: a) o Brasil é o maior país da América Latina; b) o país possui má distribuição de renda, ou seja, desigualdade social (ONU, 2018); c) o Brasil ocupa o 42 - lugar no ranking da desigualdade salarial em uma lista de 44 países, na frente apenas da Costa Rica e África do Sul (OCDE, 2018). 
De acordo com Fox e Fox (2008), a questão da desigualdade salarial tem sido ignorada pelo mercado de trabalho. Os autores consideram isso lamentável, porque há décadas o número de mulheres no mercado de trabalho tem se elevado. Além disso, os autores destacam que, em decorrência das mudanças estruturais, o mercado de trabalho aumentou a demanda por mulheres, e a oferta de empregos para elas continuará a crescer em todos os setores. Nesse sentido, a pesquisa contribui para observar esse problema em um contexto específico.

A pesquisa, ao analisar todas as regiões geográficas do Brasil, amplia as conclusões do estudo de Silva, Dal Magro e Silva (2016), o qual encontrou fatores que explicam o salário dos contadores em regiões específicas. Para Haynes (2017), a contabilidade é uma construção política conhecida por perpetuar a desigualdade salarial, principalmente devido aos desafios globais relacionados ao gênero, que, ao longo da história, representam uma barreira difícil de superar.

Considerando que os contadores, em suas diferentes ocupações (cargos) são disseminadores e perpetuadores das informações das empresas, este estudo se justifica por centrar atenção em profissionais que representam empresas que são, em um sentido amplo, organizações. Dessa forma, a profissão contábil deveria ser um exemplo para a sociedade, demonstrando que na contabilidade a desigualdade salarial deve ser a menor possível. Assim, possivelmente a área contábil é um campo promissor para este estudo.

Além disso, para que seja possível desenvolver ações que minimizem a discriminação salaria na área contábil, é necessário compreender as causas das diferenças salariais entre os diferentes cargos na contabilidade. Portanto, conhecer os determinantes da diferença salarial da área contábil contribui para a reflexão e implementação de ações que reduzam as disparidades salariais, especialmente no que se refere às lacunas endógenas para fatores discriminatórios, uma vez que a solução desse problema contribui para o desenvolvimento da profissão. Isso é importante porque pode indicar uma maior solidez da profissão no mercado de trabalho, além de estimular os trabalhadores ingressantes e consolidar a atuação da categoria no cenário nacional.

Diante disso, uma importante contribuição desta pesquisa resulta da possibilidade de dimensionar os fatores que geram a discriminação salarial (fonte do problema), pois identifica variáveis que exigem maior atenção daqueles que atuam na área contábil, como profissionais ou acadêmicos.

Conhecer as forças discriminatórias também contribui para a identificação das principais desigualdades que afetam a distribuição de renda de uma população. Os resultados podem subsidiar os formuladores de políticas a projetarem medidas redistributivas, bem como a avaliação de seu impacto no bem-estar de uma sociedade (CASTELLANO, MANNA e PUNZO, 2016). Efetivamente, conhecer os determinantes é importante para a escolha das melhores políticas públicas (CAMPANTE, CRESPO e LEITE, 2004); tais políticas podem reduzir as diferenças salariais e melhor a distribuição de renda.

A pesquisa também contribui por considerar a heterogeneidade das regiões geográficas brasileiras. Com essa estratégia empírica, espera-se que os resultados evidenciem as diferenciais salariais entre as regiões do país. Além disso, há uma disparidade salarial entre homens e mulheres, em que os resultados da pesquisa possibilitam oferecer subsídios para estabelecer uma agenda que promova a igualdade salarial. No que diz respeito à experiência dos profissionais de contabilidade, a pesquisa revela informações sobre as habilidades formais dos contadores. Considerando a experiência no trabalho contábil como essencial, políticas públicas podem fornecer treinamentos específicos para as regiões brasileiras.

\section{REFERENCIAL TEÓRICO}

A teoria do capital humano e a teoria da segmentação são apresentadas nas seções a seguir a partir de estudos anteriores, com destaque para as variáveis de análise e resultados que contribuem para o trabalho proposto nesta pesquisa.

\section{A teoria do capital humano e a teoria da segmentação}

De acordo com Helal (2005), os teóricos da teoria do capital humano (por exemplo, Becker, 1964 e Mincer, 1974), consideram que, quanto maior for o capital humano do indivíduo, maior a sua produtividade. Consequentemente, mais elevado o valor econômico deste indivíduo ao mercado de trabalho, assim como maior sua possibilidade de conseguir um trabalho. 
Conforme discutido por Pfeffer e Langton (1988), a teoria do capital humano prevê que as mudanças nas características demográficas e de produtividade podem levar a lacunas nos salários, independentemente das normas ou arranjos corporativos. Por sua vez, Hanushek (2013) destaca que os estudos de Schultz (1961), Becker (1964) e, em especial o de Mincer (1970, 1974) contribuíram para disseminar a abordagem teórica e empírica da teoria do capital humano. Isso porque eles mostraram que a diferença salarial é causada por diferenças de habilidade, isto é, pelo capital humano.

Posteriormente, por meio de um estudo de revisão, Neves e Fernandes (2002) observaram que as variáveis escolaridade e experiências são frequentemente utilizadas. A escolaridade é considerada o principal fator do capital humano. Para os autores, a estrutura ocupacional (ocupação) e a posição de classe (base da autoridade gerencial) são relevantes para explicar o processo de formação salarial.

Além disso, a posição da classe desempenha uma função importante como mediadora entre escolaridade e salário. Ainda em relação à educação, Mincer (1974) argumenta que a educação é responsável pelas habilidades. Como resultado, essa variável tem sido usada como um proxy para medir o capital humano e entender a desigualdade salarial.

Igbaria e Chidambaram (1997) investigaram a diferença de gênero, variáveis de capital humano (idade, experiência, escolaridade e cargo) e fatores que explicam o sucesso na carreira. Os achados relativos às mulheres são: a) geralmente têm menor escolaridade; b) têm menos tempo de trabalho; c) têm menos habilidades profissionais e gerenciais. Os autores atribuíram essas diferenças ao maior volume de atividades desempenhadas pelas mulheres e às interrupções na carreira para priorizar a família. Adicionalmente, concluem que o capital humano pode ser explicado pelas escolhas voluntárias dos indivíduos na alocação de investimentos como tempo e esforço no trabalho e na família.

No entanto, a teoria do capital humano tem sido criticada. Helal (2005), o qual considera que essa abordagem teórica é restritiva, por ser uma abordagem econômica neoclássica, ignora características sociais associadas ao emprego e à determinação dos salários. Além disso, Darity (1993) observa que, desde 1970, a teoria da segmentação é uma base teórica alternativa ou complementar à teoria do capital humano a qual tem sito adotada para explicar o comportamento do mercado de trabalho.

A teoria da segmentação pressupõe que as mudanças, reestruturação e descentralização do mercado de trabalho podem fornecer informações sobre como as identidades do mercado de trabalho são produzidas a partir da experiência adquirida pela experiência e representações locais (BAUDER, 2001). Segundo Bauder (2001), em contraste com a teoria do capital humano, a teoria da segmentação defende que trabalhadores e empregos não são compatíveis com um mecanismo universal de mercado. Em vez disso, os empregos são divididos em segmentos dentro do mercado de trabalho, ou seja, tipo de trabalho (ocupação) e posição.

Assim, a teoria da segmentação constitui uma lente teórica útil para explicar a marginalização econômica dos trabalhadores, de minorias raciais, bem como de mulheres (BAUDER, 2001). Morrison (1990) explicou que, para melhorar a teoria da segmentação, é necessário criar uma conexão entre teoria e prática. Além disso, o mercado de trabalho deve ser considerado em seu contexto geográfico (local, regional, espacial). Dibb e Simkin (2009) relatam que algumas pesquisas se dedicaram a analisar a "prática" em que ocorre a segmentação. Observa-se que tanto a Teoria do Capital Humano quanto a Teoria da Segmentação não estão livres de críticas e ambas possuem limitações.

No entanto, as limitações das teorias não minimizam sua relevância como um guia a se aplicar em setores empresariais e econômicos. No caso desta pesquisa, a teoria do capital humano é adotada para explicar os salários, de acordo com a escolaridade, qualificações, formação e experiência profissional. Por sua vez, a teoria da segmentação, além de explicar a escolaridade, considera que os salários estão mais relacionados ao tipo de ocupação/cargo dos trabalhadores, particularmente nesta pesquisa: a auxiliares contábeis, auditores e contadores.

\section{Determinantes da desigualdade salarial}

Os aspectos relativos à diferença salarial atraem a atenção de inúmeras organizações públicas e privadas. Por sua vez, no contexto acadêmico, as pesquisas se apoiam em diferentes perspectivas epistemologia, no entanto, tanto na perspectiva fenomenológica quanto positivista, os pesquisadores têm por objetivo compreender antecedentes, consequentes e contextos das diferenças salariais. Eles também buscam identificar fatores motivadores da desigualdade salarial entre os trabalhadores, ampliando o escopo das pesquisas sobre desigualdades sociais. 
Nesse sentido, Dunlop (1957), ao considerar que a ausência de acordos coletivos para a fixação de salários pode implicar em diferenças salariais no mesmo município, Estado, região ou país, evidenciou como relevante a realização de acordos coletivos regionais.

Em relação à raça e à diferença salarial por região geográfica, Campante, Crespo e Leite (2004) explicam que, no Brasil, há um fenômeno conhecido como "embranquecimento", ou seja, um indivíduo pobre se autodenomina como negro ou pardo, diferentemente daquele com melhor poder aquisitivo que, mesmo tendo as mesmas características do primeiro grupo, se identifica como branco. Esse comportamento pode influenciar os resultados das pesquisados sobre a diferença salarial entre brancos e negros, especialmente no Nordeste e Sudeste do Brasil. Para os autores, outro fator significativo no aumento da discriminação salarial é a escolaridade, sendo que raça e escolaridade tendem a influenciar a entrada no mercado de trabalho e salários.

Fields e Yoo (2000) quantificaram a importância de fatores que contribuem para a redução da desigualdade salarial na Coreia. Os fatores identificados na pesquisa são: ocupação ou experiência, gênero, escolaridade, salário da ocupação, tamanho da empresa e região. Dentre os fatores identificados, concluíram que os mais importantes para explicar a desigualdade salarial são: escolaridade, ocupação e experiência. Além disso, descobriram que a desigualdade salarial diminuiu entre os homens, mas não entre as mulheres.

Hossain, Haque e Haque (2015) investigaram os fatores que determinam os diferenciais salariais em Bangladesh. O estudo concluiu que a escolaridade, idade e gênero determinam as diferenças salariais. Os autores sugerem que tais fatores devem ser considerados pelos formuladores de políticas para melhorar a distribuição de renda.

Nos países africanos, Agbodji, Batana e Ouedraogo (2015) investigaram a desigualdade de gênero, bem como as desigualdades regionais. Em relação ao gênero, constataram que as mulheres recebem salários inferiores aos homens. Nesse contexto, Dreher, Gehring e Klasen (2015) constataram que a desigualdade de gênero é um dos principais indicadores que afeta os países em desenvolvimento. Para Jayachandran (2015), os homens têm salários superiores ao das mulheres em quase todos os países, embora nos últimos anos, nos países em desenvolvimento, a diferença salarial tem se reduzindo no decorrer dos anos, mesmo que ainda haja diferença. No entanto, segundo o observado pelos autores, há uma tendência ao consenso de que, independentemente do país, há ou deveria haver ações políticas para erradicar tal desigualdade.

Conforme relatado pela Fox (1981), a disparidade entre homens e mulheres em relação ao salário, poder e prestígio ocorre em quase todo o mundo. Na pesquisa da Fox (1981), que comparou os salários de homens e mulheres, o autor concluiu que os salários das mulheres são inferiores ao dos homens. Concluem também que os homens são menos suscetíveis às variações salariais devido a diferenças de raça e nacionalidade.

Konrad e Pfeffer (1990) analisaram os fatores que afetam a relação entre produtividade, publicações e remuneração. Com base em uma amostra de 5.645 pesquisadores universitários de 200 instituições de ensino, os autores concluíram que a produtividade explica os salários e que a teoria do capital humano explica essa relação. Por sua vez, Gerhart e Milkovich (1990) avaliaram os determinantes e as consequências das diferenças salariais entre um grupo de gestores de nível superior e médio. Para isso, utilizaram dados longitudinais de 14 mil gestores de 200 instituições de ensino. Apesar de terem concluído que há diferenças salariais significativas, a pesquisa foi incapaz de identificar os determinantes da diferença salarial.

No contexto da contabilidade, Fields (2003) investigou a desigualdade salarial nos Estados Unidos de 1979 a 1999. As variáveis explicativas incluem gênero, raça, experiência (tempo de emprego), escolaridade, ocupação, setor econômico e região geográfica. $\mathrm{O}$ autor conclui que as variáveis explicativas da desigualdade salarial são escolaridade, ocupação, experiência (tempo de emprego) e gênero. Por sua vez, Bruno (2010), com o objetivo de analisar as diferenças salariais dos tunisianos no mercado de trabalho em Paris, fez uma pesquisa semelhante. Utilizando um modelo de regressão linear, o autor concluiu que, para a amostra, gênero e nacionalidade não foram significativos. Todavia, quando a amostra foi estratificada segundo o setor econômico, o estudo identificou diferenças salariais significativas entre mulheres e homens, estrangeiros e cidadãos nativos.

De acordo com Haynes (2008), nos países desenvolvidos, cada vez mais mulheres e homens têm igualdade nos cargos ocupados, direitos legais, acesso à educação e poder de voto. As mulheres têm sido ativas em áreas anteriormente dominadas por homens, ou seja, diversificaram suas funções. No entanto, embora existam melhorias em termos de igualdade formal, as desigualdades e os problemas permanecem. Exemplos destacados no estudo são: (i) poucas mulheres em altos cargos políticos e empresariais; (ii) desequilíbrio no trabalho doméstico (sobrecarga para as mulheres); (iii) salário desigual e; (iv) assédio sexual. 
Por sua vez, Silva, Dal Magro e Silva (2016) tiveram como objetivo identificar as desigualdades de gênero na contabilidade, analisadas a partir da perspectiva do Glass Ceiling. Investigaram trabalhadores na região sul do Brasil. Os resultados revelaram que os homens ocupam mais frequentemente os cargos de auditor e contador. Além disso, os homens têm salários mais elevados, bem como os cargos ocupados por homens são mais frequentes em grandes empresas. Assim, os autores concluíram que há o teto de vidro na carreira contábil, o que cria uma barreira invisível no acesso das mulheres a cargos de maior prestígio e melhores salários.

A pesquisa de Castellano, Manna e Punzo (2016) teve como objetivo identificar os fatores que explicam a diferença salarial na França e na Itália. Para tanto, utilizam dados do período anterior a crise econômica (2004 a 2007). As variáveis examinadas foram gênero, idade, escolaridade, experiência (tempo de trabalho), ocupação e salário. Os resultados confirmaram que, na Itália, as políticas redistributivas pioram a desigualdade e na França o efeito é mitigado pela fixação de cargos e salários e políticas sociais. Além disso, os autores enfatizam que a França é tradicionalmente mais igualitária do que a Itália. Em outras palavras, a Itália, mesmo com uma proporção semelhante de indivíduos de cada gênero, apresenta uma maior disparidade salarial comparativamente à França.

Recentemente Haynes (2017) ao considerar, em um contexto amplo, que nos últimos 25 anos muitas coisas mudaram, pondera que poucas mudanças ocorreram em relação à desigualdade salarial de gênero na área contábil. Embora tenha havido avanço na profissão contábil, as desigualdades persistem e é preocupante. Uma mudança importante identificada pela autora é que as mulheres podem agora escolher empregos mais flexíveis, especialmente de meio período.

A possibilidade de trabalho em meio período possibilita às mulheres realizar múltiplas tarefas, especialmente aquelas relacionadas aos cuidados dos filhos e às tarefas domésticas. No entanto, as mulheres que optam por reduzir temporariamente a sua carga de trabalho por conta da atenção à família tendem a ser prejudicadas. Em muitos casos, para essas mulheres, isso torna difícil melhorar sua carreira, bem como sofrem imputação de estereótipos depreciativos e discriminação. No entanto, acima de tudo, há a questão explícita de receber salários mais baixos.

\section{PROCEDIMENTOS METODOLÓGICOS}

Esta pesquisa é classificada como descritiva, documental e quantitativa. Os dados foram coletados na base de micro dados do Relação Anual de Informações Sociais (RAIS), disponível no site do Ministério do Trabalho e Emprego (MTE). O período selecionado foi de 2009 a 2015, ou seja, sete anos. A RAIS é um banco de dados do governo para controle do mercado de trabalho. Neste banco de dados, todas as empresas do país relatam anualmente, de forma obrigatória, os dados sobre seus funcionários (salários, bônus, carga de trabalho, tempo, dentre outros). Portanto, permite a geração de dados estatísticos do censo longitudinal sobre os funcionários do mercado de trabalho formal.

A amostra selecionada para estudo (após o processamento dos dados brutos) é composta por profissionais contábeis, com os cargos de Auditor, Contador e Auxiliar Contábil. Respectivamente, o registro do contrato de trabalho, de acordo com o relatório do Código Ocupacional Brasileiro (CBO), refere-se aos cargos de: Auditor - CBO 252205, Contador - CBO 252210 e Auxiliar Contábil - CBO 413110.

Deve-se ressaltar que a população de trabalhadores contábeis inclui somente empregados contratados para atuarem nesses cargos e não contempla sócios ou qualquer outro regime de contratação. Assim, o tamanho da amostra é composto por: 60.447 observações para 2009; 72.676 observações para 2010; 86.585 observações para 2011; 88.013 observações para 2012; 91.817 observações para 2013; 91.104 observações para 2014; e 80.881 para 2015.

Todos os dados anuais foram baixados do banco de dados do MTE e transferidos no software Access pela Microsoft Corporation ${ }^{\circledR}$. O primeiro objetivo foi filtrar os dados para as três ocupações a serem analisadas nos sete anos. Posteriormente, os dados filtrados foram transferidos para o software Excel. Nesta fase, foram excluídos os dados com possível erro de registro reportados à base do MTE pelas empresas empregadoras. Nesta etapa, foi excluído os registros referentes à funcionários que não concluíram o ensino médio e os classificados como inativos.

Finalmente, as seguintes variáveis foram tabuladas: pagamento (soma de salário, bônus e outras remunerações), cargo, gênero, raça, idade, escolaridade, tipo de deficiência, tamanho da empresa (número de trabalhadores), tipo de movimento (contratação, demissão, trabalho normal ou licença no ano do relatório) e o Estado (agrupados por região geográfica). 
Os valores dos salários e outras remunerações, no período de 2009-2014, foram monetariamente atualizados para o ano de 2015. Isso foi feito com base no Índice Geral de Preços de Mercado (IGP-M), estimado pela Fundação Getulio Vargas/Brasil (FGV). Assim, foi possível estimar o salário anual e médio para o modelo de regressão múltipla com variáveis binárias. Para a análise estatística, as variáveis foram categorizadas de acordo com o Quadro 1.

Quadro 1

\section{Categorização de variáveis}

\begin{tabular}{|c|c|c|}
\hline Variáveis & Categorização & Referências \\
\hline $\begin{array}{l}\text { Salário mensal (ganho } \\
\text { total- soma: salário, } \\
\text { bônus e outros) }\end{array}$ & $\begin{array}{c}\text { Valor monetário } \\
\text { (R\$- Reais- 2009/2015) }\end{array}$ & $\begin{array}{l}\text { Raposa (1981); Konrad e Pfeffer (1990); Gerhart e Milkovich (1990); Campos e Yoo (2000); } \\
\text { Campos (2003); Haynes (2008); Bruno (2010); Agbodji, Batana e Ouedraogo (2015); } \\
\text { Brighenti, Jacomossi e Silva (2015); Dreher, Gehring e Klasen (2015); Hossain, Haque } \\
\text { e Haque. (2015); Jayachandran (2015); Silva, Dal Magro e Silva (2016); Haynes (2017). }\end{array}$ \\
\hline Ocupação & $\begin{array}{l}\text { Auditor } \\
\text { Auxiliar Contábil } \\
\text { Contador }\end{array}$ & Fields e Yoo (2000); Brighenti, Jacomossi e Silva (2015); Silva, Dal Magro e Silva (2016). \\
\hline Gênero & $\begin{array}{l}\text { Masculino } \\
\text { Feminino }\end{array}$ & $\begin{array}{l}\text { Raposa (1981); Campos e Yoo (2000); Campos (2003); Haynes (2008); Bruno (2010); } \\
\text { Agbodji, Batana e Ouedraogo (2015); Brighenti, Jacomossi e Silva (2015); Dreher, } \\
\text { Gehring e Klasen (2015); Hossain, Haque e Haque (2015); Jayachandran (2015); Silva, } \\
\text { Dal Magro e Silva (2016); Haynes (2017). }\end{array}$ \\
\hline Raça & $\begin{array}{c}\text { Branco } \\
\text { Índio } \\
\text { Negro } \\
\text { Asiático } \\
\text { Mulato } \\
\text { Nenhuma etnia definida }\end{array}$ & Campos (2003); Campante, Crespo e Leite (2004). \\
\hline Faixa etária & $\begin{array}{c}15 \text { a } 17 \\
18 \text { a } 24 \\
25 \text { a } 29 \\
30 \text { a } 39 \\
40 \text { a } 49 \\
50 \text { a } 64 \\
65 \text { anos ou mais }\end{array}$ & Brighenti, Jacomossi e Silva (2015); Silva, Dal Magro e Silva (2016). \\
\hline Escolaridade & $\begin{array}{c}\text { Ensino Médio Completo } \\
\text { Ensino Superior } \\
\text { Incompleto } \\
\text { Ensino Superior } \\
\text { Completo }\end{array}$ & $\begin{array}{l}\text { Gerhart e Milkovich (1990); Campos e Yoo (2000); Campos (2003); Campante, Crespo } \\
\text { e Leite (2004); Brighenti, Jacomossi e Silva (2015); Hossain, Haque e Haque (2015); } \\
\text { Silva, Dal Magro e Silva (2016). }\end{array}$ \\
\hline Deficiência & $\begin{array}{c}\text { Física } \\
\text { Auditiva } \\
\text { Visual } \\
\text { Mental } \\
\text { Múltipla } \\
\text { Reabilitado } \\
\text { Não Deficiente }\end{array}$ & Ministério do Trabalho e Emprego (2016). \\
\hline
\end{tabular}




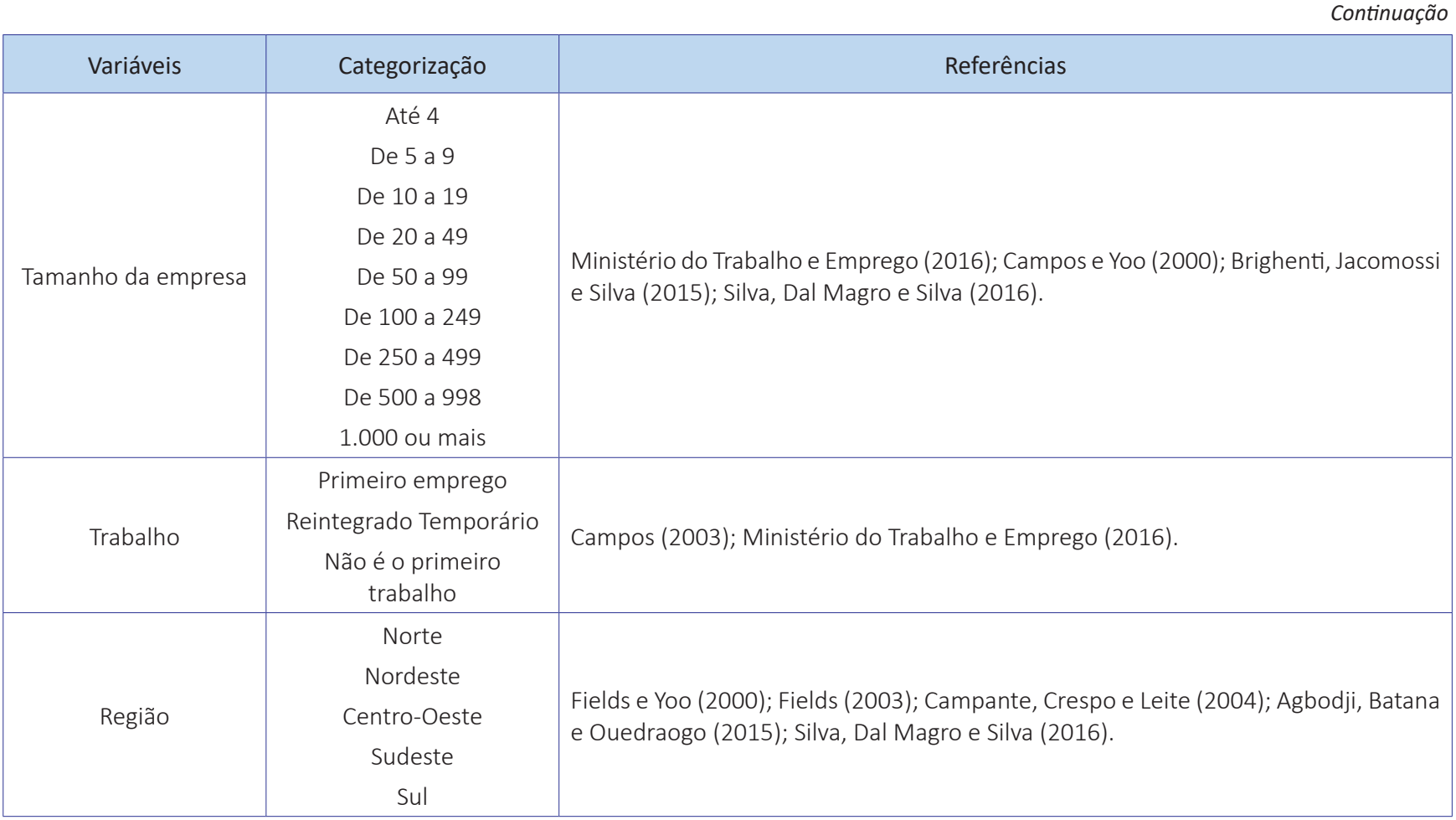

Fonte: Dados da pesquisa.

$\mathrm{Na}$ análise estatística, foi utilizada a metodologia de regressão múltipla com variáveis binárias (dummies), que assumem valores de 0 e 1 (GUJARATI e PORTER, 2011). As regressões foram realizadas usando o software estatístico STATA ${ }^{\circ}$. A partir desse método, foi possível identificar um indivíduo padrão para então compará-lo aos demais indivíduos da amostra.

Observações ex-ante e testes complementares mostraram que: (i) os dados são normais (com base no tamanho da amostra); (ii) não há problemas de multicolinearidade (perfeita), facilmente observável pelas variáveis escolhidas (apenas variáveis dummies no lado direito das equações para análise de regressão); (iii) não há autocorrelação dos resíduos, pois são regressões em dados transversais; (iv) não há heterocedasticidade, uma vez que não têm variáveis explicativas não binárias e; (v) não há micronumerosidade devido ao tamanho da amostra.

\section{ANÁLISE E DISCUSSÃO DE DADOS}

A análise dos dados foi realizada comparativamente através do modelo de regressão múltipla com variáveis binárias, com base no cargo do contador. A posição do contador (modelo padrão) é omitida nos resultados do modelo estatístico. Essa omissão é uma característica dos modelos computacionais de estimação para o modelo adotado, uma vez que as outras posições são comparadas ao modelo padrão, pela indicação da diferença percentual (conforme mostrado em qualquer resultado desse tipo de estimativa, para qualquer software). 0 resultado é apresentado na Tabela 1. 
Tabela 1

Modelo estatístico para dados de 2009

\begin{tabular}{|c|c|c|c|c|c|c|}
\hline Ln salário 2009 & Coef. & Std. Err. & $\mathrm{t}$ & $P>|t|$ & \multicolumn{2}{|c|}{ [95\% Conf. Interv.] } \\
\hline Auditor & $-0,0034784$ & 0,0091547 & $-0,38$ & 0,704 & $-0,0214217$ & 0,0144649 \\
\hline Accounting Assistant & $-0,5041989(*)$ & 0,0049432 & $-102,00$ & 0,000 & $-0,5138877$ & $-0,4945102$ \\
\hline $\begin{array}{l}\text { Tamanho: } \\
5 \text { a } 9\end{array}$ & 0,0116508 & 0,0066198 & 1,76 & 0,078 & $-0,0013240$ & 0,0246256 \\
\hline 10 a 19 & $0,0848258\left(^{*}\right)$ & 0,0065152 & 13,02 & 0,000 & 0,0720560 & 0,0975956 \\
\hline 20 a 49 & $0,1681385(*)$ & 0,0063057 & 26,66 & 0,000 & 0,1557793 & 0,1804977 \\
\hline 50 a 99 & $0,2463770\left(^{*}\right)$ & 0,0069578 & 35,41 & 0,000 & 0,2327397 & 0,2600142 \\
\hline 100 a 249 & $0,2850203(*)$ & 0,0066012 & 43,18 & 0,000 & 0,2720820 & 0,2979586 \\
\hline 250 a 499 & $0,3366667(*)$ & 0,0078948 & 42,64 & 0,000 & 0,3211929 & 0,3521404 \\
\hline 500 a 999 & $0,3449819(*)$ & 0,0093169 & 37,03 & 0,000 & 0,3267207 & 0,3632431 \\
\hline Above 999 & $0,4693768\left(^{*}\right)$ & 0,0097095 & 48,34 & 0,000 & 0,4503461 & 0,4884074 \\
\hline $\begin{array}{l}\text { Escolaridade: } \\
\text { Ensino Médio Completo }\end{array}$ & $-0,3437659\left(^{*}\right)$ & 0,0050210 & $-68,47$ & 0,000 & $-0,3536072$ & $-0,3339247$ \\
\hline $\begin{array}{l}\text { Ensino Superior } \\
\text { Incompleto }\end{array}$ & $-0,1962161(*)$ & 0,0052004 & $-37,73$ & 0,000 & $-0,2064088$ & $-0,1860234$ \\
\hline $\begin{array}{l}\text { Idade: } \\
15 \text { a } 17\end{array}$ & $-0,3682908(*)$ & 0,0229653 & $-16,04$ & 0,000 & $-0,4133029$ & $-0,3232787$ \\
\hline 18a 24 & $-0,2471285\left(^{*}\right)$ & 0,0051779 & $-47,73$ & 0,000 & $-0,2572773$ & $-0,2369798$ \\
\hline 25 a 29 & $-0,1141342\left(^{*}\right)$ & 0,0051368 & $-22,22$ & 0,000 & $-0,1242024$ & $-0,1040661$ \\
\hline 40 a 49 & $0,0700979\left(^{*}\right)$ & 0,0068116 & 10,29 & 0,000 & 0,0567470 & 0,0834487 \\
\hline 50 a 64 & $0,0500103(*)$ & 0,0107229 & 4,66 & 0,000 & 0,0289934 & 0,0710272 \\
\hline 65 ou mais & $-0,1651046\left(^{*}\right)$ & 0,0517790 & $-3,19$ & 0,001 & $-0,2665916$ & $-0,0636177$ \\
\hline Branco & $-0,5942114\left(^{*}\right)$ & 0,0490335 & $-12,12$ & 0,000 & $-0,6903172$ & $-0,4981057$ \\
\hline Índio & $-0,0795907$ & 0,0455734 & $-1,75$ & 0,081 & $-0,1689147$ & 0,0097332 \\
\hline Negro & $-0,0411013(*)$ & 0,0107514 & $-3,82$ & 0,000 & $-0,0621740$ & $-0,0200285$ \\
\hline Asiático & $0,0574381(*)$ & 0,0203516 & 2,82 & 0,005 & 0,0175490 & 0,0973273 \\
\hline Mulato & $-0,0484528(*)$ & 0,0048974 & $-9,89$ & 0,000 & $-0,0580518$ & $-0,0388539$ \\
\hline Nenhuma etnia definida & 0,0023379 & 0,0084505 & 0,28 & 0,782 & $-0,0142250$ & 0,0189009 \\
\hline Feminino & $-0,0949639\left(^{*}\right)$ & 0,0038325 & $-24,78$ & 0,000 & $-0,1024755$ & $-0,0874522$ \\
\hline $\begin{array}{l}\text { Deficiência: } \\
\text { Física }\end{array}$ & $-0,1515977\left(^{*}\right)$ & 0,0453535 & $-3,34$ & 0,001 & $-0,2404906$ & $-0,0627047$ \\
\hline Auditiva & 0,0085802 & 0,0586156 & 0,15 & 0,884 & $-0,1063067$ & 0,1234670 \\
\hline Visual & 0,1705001 & 0,9695885 & 0,18 & 0,860 & $-1,7298970$ & 2,0708970 \\
\hline Mental & $-0,1510264$ & 0,3202406 & $-0,47$ & 0,637 & $-0,7786990$ & 0,4766462 \\
\hline Deficiência múltipla & $-0,3006791$ & 0,3201747 & $-0,94$ & 0,348 & $-0,9282225$ & 0,3268643 \\
\hline Reabilitação & 0,2456006 & 0,1848923 & 1,33 & 0,184 & $-0,1167890$ & 0,6079902 \\
\hline $\begin{array}{l}\text { Tipo de trabalho: } \\
\text { Primeiro emprego }\end{array}$ & $-0,0946160\left(^{*}\right)$ & 0,0065336 & $-14,48$ & 0,000 & $-0,1074220$ & $-0,0818101$ \\
\hline Reintegrado & 0,0254369 & 0,0470334 & 0,54 & 0,589 & $-0,0667486$ & 0,1176224 \\
\hline Temporário & $-0,0201764$ & 0,0268535 & $-0,75$ & 0,452 & $-0,0728093$ & 0,0324566 \\
\hline $\begin{array}{l}\text { Região: } \\
\text { Norte }\end{array}$ & $-0,1775697\left(^{*}\right)$ & 0,0105908 & $-16,77$ & 0,000 & $-0,1983277$ & $-0,1568117$ \\
\hline Nordestet & $-0,3013411\left(^{*}\right)$ & 0,0060224 & $-50,04$ & 0,000 & $-0,3131450$ & $-0,2895373$ \\
\hline Sul & $-0,1274950\left(^{*}\right)$ & 0,0050477 & $-25,26$ & 0,000 & $-0,1373886$ & $-0,1176015$ \\
\hline Centro-Oeste & $-0,1540139\left(^{*}\right)$ & 0,0069476 & $-22,17$ & 0,000 & $-0,1676312$ & $-0,1403966$ \\
\hline _ constante & $8,05644(*)$ & 0,0065668 & 1226,84 & 0,000 & 8,043569 & 8,069311 \\
\hline$R^{2}$ & & & & & & \\
\hline Sem observações & & & & & & \\
\hline
\end{tabular}

Obs: $\left({ }^{*}\right)$ Estatisticamente significativo em $5 \%$

Fonte: Dados da pesquisa. 
O indivíduo padrão, estabelecido para diferenciar as demais posições, devido ao alto salário, foi: a) ocupa o cargo de contador; b) homem; c) branco; d) idade entre 30 e 39 anos; e) graduado (ensino superior completo); f) não tem deficiência; g) pelo menos no segundo emprego; h) trabalha em uma empresa com até quatro funcionários; i) na região Sudeste. A escolha desse indivíduo é justificada pelas seguintes razões: 1) é o profissional com maior salário médio entre os cargos (no período estudado); 2) é o principal profissional na área contábil, sendo responsável pela contabilidade das empresas.

A análise comparativa é descrita nas Tabelas 1, 2, 3 e 4. A Tabela 2 mostra algumas das variáveis e suas variações percentuais em relação ao indivíduo padrão.

Tabela 2

Variação percentual em relação ao indivíduo padrão

\begin{tabular}{|c|c|c|c|c|c|c|c|}
\hline Descrição & 2009 & 2010 & 2011 & 2012 & 2013 & 2014 & 2015 \\
\hline $\begin{array}{l}\text { Salário Contador } \\
\text { (mensal) } * *\end{array}$ & 3.154 & 3.351 & 3.473 & 3.490 & 3.550 & 3.515 & 3.217 \\
\hline \multicolumn{8}{|c|}{ Variação percentual em relação ao salário de: } \\
\hline Auditor & $*$ & $161,4 \%$ & $108,7 \%$ & $*$ & $91,4 \%$ & $90,0 \%$ & $91,8 \%$ \\
\hline Auxiliar Contábil & $49,6 \%$ & $49,7 \%$ & $48,8 \%$ & $51,0 \%$ & $51,6 \%$ & $52,6 \%$ & $47,6 \%$ \\
\hline $\begin{array}{l}\text { Primeiro } \\
\text { emprego }\end{array}$ & $90,5 \%$ & $93,1 \%$ & $93,5 \%$ & $92,5 \%$ & $92,6 \%$ & $91,8 \%$ & $86,2 \%$ \\
\hline Temporário & $*$ & $92,0 \%$ & $93,4 \%$ & $*$ & $97,4 \%$ & $92,5 \%$ & $*$ \\
\hline Feminino & $90,5 \%$ & $90,0 \%$ & $90,3 \%$ & $90,8 \%$ & $89,9 \%$ & $89,9 \%$ & $91,4 \%$ \\
\hline Asiático & $105,7 \%$ & $105,7 \%$ & $107,0 \%$ & $105,4 \%$ & $*$ & $95,1 \%$ & $*$ \\
\hline Mulato & $95,2 \%$ & $92,1 \%$ & $94,0 \%$ & $95,4 \%$ & $95,5 \%$ & $94,5 \%$ & $93,2 \%$ \\
\hline Negro & $95,9 \%$ & $93,5 \%$ & $92,6 \%$ & $94,0 \%$ & $93,9 \%$ & $92,6 \%$ & $93,4 \%$ \\
\hline $\begin{array}{l}\text { Nenhuma raça } \\
\text { definida }\end{array}$ & $*$ & $98,5 \%$ & $98,4 \%$ & $98,6 \%$ & $*$ & $97,8 \%$ & $98,6 \%$ \\
\hline $\begin{array}{l}\text { Ensino Médio } \\
\text { Completo }\end{array}$ & $65,6 \%$ & $63,5 \%$ & $63,7 \%$ & $65,3 \%$ & $66,3 \%$ & $66,7 \%$ & $66,5 \%$ \\
\hline $\begin{array}{l}\text { Ensino Superior } \\
\text { Incompleto }\end{array}$ & $80,4 \%$ & $77,7 \%$ & $77,2 \%$ & $77,1 \%$ & $77,1 \%$ & $77,3 \%$ & $73,5 \%$ \\
\hline Deficiência física & $84,8 \%$ & $*$ & $91,4 \%$ & $83,1 \%$ & $80,1 \%$ & $82,9 \%$ & $78,6 \%$ \\
\hline $\begin{array}{l}\text { Deficiência } \\
\text { Auditiva }\end{array}$ & $*$ & * & $*$ & $68,5 \%$ & $78,5 \%$ & $86,1 \%$ & $85,7 \%$ \\
\hline
\end{tabular}

Fonte: Dados da pesquisa.

* O modelo não apresentou significância estatística no nível de 5\%, para a variável.

* O padrão estabelecido pelo modelo: contador, homem, branco, idade entre 30 e 39 anos, ensino superior completo (graduado), sem deficiência, está pelo menos atuando no segundo emprego, trabalha em uma empresa com até quatro funcionários e que é da região Sudeste.

De acordo com os resultados, o salário médio do auditor em 2010 foi 161,4\% superior ao salário médio do contador, com significância de $5 \%$. No entanto, no período estudado houve uma redução significativa no valor do salário médio do auditor. Em 2013, pode-se observar que o salário médio do auditor passou a ser $(8,6 \%)$ menor do que o salário do contador. Isso deve ser investigado em pesquisas futuras, uma vez que há uma tendência de que os auditores tenham salários mais elevados do que os contadores.

No caso do auxiliar contábil, 2014 foi o ano de maior variação percentual dos salários, uma vez que o salário médio do auxiliar contábil em relação ao salário do contador teve variação de 52,6\%. Entretanto, no período estudado, essa proporção oscilava entre $47,6 \%$ e $52,6 \%$ do salário do contador, ou seja, uma oscilação baixa (de 5 pontos percentuais), mesmo com variações positivas e negativas nessa proporção. Isso significa que não havia nenhuma tendência clara de ganhos salariais reais proporcionalmente ao cargo de contador. 
Esses resultados se destacam e pode-se inferir que tal comportamento deriva da crise econômica que afetou o Brasil desde 2014. Como se pode observar, esse resultado foi repetido para todos os cargos (contador, auditor e auxiliar contábil) e salários. Além disso, a queda nos salários em 2015 pode ser explicada, pois, segundo o Instituto Brasileiro de Geografia e Estatística (IBGE, 2018), entre 2014 e 2015, houve uma redução na renda real (inflação ajustada). De acordo com levantamento realizado pela Fundação Instituto de Pesquisas Econômicas (FIPE), associada à Catho, de 2014 a 2015 o Brasil sofreu redução de 2\% no valor dos salários de contratação. Isso representa o pior resultado dos últimos 11 anos (CATHO, 2018). Na área contábil, a redução salarial foi mais drástica, certamente impactada pela redução do número de vagas ocupadas, com repercussões nos salários.

Para o tipo de emprego mostrado na Tabela 1, o indivíduo padrão é o profissional que não está em seu primeiro emprego. Em outras palavras, o funcionário já tem alguma experiência em contabilidade ou em outra área. Observa-se que esse trabalhador tem salário mais alto em todos os anos analisados. Mesmo em comparação com os outros que estão no primeiro emprego, ou no trabalho temporário. Isso pode ser explicado por sua experiência no mercado de trabalho (tempo de trabalho), que está em linha com os resultados de Fields e Yoo (2000) e Brighenti, Jacomossi e Silva (2015). Fields e Yoo (2000) consideram a experiência como um dos fatores mais importantes para explicar a desigualdade salarial.

Além disso, a variação salarial no geral apresenta redução de 2010 até 2015, tendo pequenas oscilações no período. Para um profissional em seu primeiro emprego, o valor do salário foi $86,2 \%$ em relação ao salário do profissional que não está em seu primeiro emprego (indivíduo padrão); e em relação ao trabalho temporário, a menor variação foi registrada em 2010 (92\%). Assim, percebe-se que o profissional que não está em seu primeiro emprego recebe um salário mais alto do que outros profissionais. Isso pode ser explicado pela experiência profissional. No entanto, constata-se que a variação salarial entre os tipos de empregos foi pequena, uma vez que não apresenta uma diferença relevante.

Em relação ao gênero, houve redução nos salários proporcionais das mulheres de 2009 a 2014, e aumentou em 2015 (91,4\% do salário médio dos homens). Isto é, em 2015, as mulheres tinham salários um pouco mais próximo do indivíduo padrão, esse que é um homem. Durante o período, a diferença entre homens e mulheres foi de aproximadamente $10 \%$ a favor dos homens. No entanto, o cenário de salários mais baixos para as mulheres foi repetido ao longo dos anos, mostrando que os homens ainda são mais valorizados quando comparados às mulheres.

A evidência da desigualdade salarial entre homens e mulheres no Brasil também é encontrada em estudos realizados em diversas regiões e Estados brasileiros, a exemplo de Brighenti, Jacomossi e Silva (2015) e Silva, Dal Magro e Silva (2016). Essa mesma realidade é vista em outros países, como relatado em Fields e Yoo (2000).

Descrito por Dreher, Gehring e Klasen (2015), a desigualdade de gênero é um dos principais problemas que afetam grande parte dos países em desenvolvimento. Além disso, para Jayachandran (2015), os homens têm salários mais altos do que as mulheres em quase todos os países/regiões e em diferentes setores econômicos. Isso pode parecer normal, mas, diante do desenvolvimento socioeconômico, é difícil aceitar que não haja mudanças significativas em relação a essa questão. Na profissão contábil especificamente, Haynes (2017) ressalta que, mesmo que tenha havido avanços, as desigualdades persistem e preocupam.

A Pesquisa Nacional por Amostra de Domicílios (PNAD) do IBGE (2018) também evidenciou que houve redução na desigualdade de renda entre homens e mulheres, de 74,5\% para 76,1\% entre 2014 e 2015 . No entanto, essa mudança pode estar relacionada à crise econômica brasileira e, portanto, pode ser temporária. Esse resultado também é confirmado por Silva, Dal Magro e Silva (2016), que constataram que ainda é difícil as mulheres assumirem cargos superiores e com salários maiores.

Ao analisar o grupo étnico (Tabela 2), nota-se não haver discriminação do salário entre negros e mulatos. As relações salariais de negros e mulatos, em comparação com o indivíduo padrão (branco) para o período estudado, estão entre $92 \%$ e $96 \%$, aproximadamente. Em outras palavras, negros e mulatos têm salários médios inferiores aos de um homem brancos na faixa de $4 \%$ a $8 \%$, aproximadamente. Uma ênfase deve ser colocada à raça asiática, que tem salários ligeiramente mais elevados do que os brancos, em torno de $5 \%$ durante a maior parte do período analisado.

Quanto à educação, os indivíduos com ensino médio completo têm salários mais baixos, em comparação com aqueles com ensino superior incompleto e completo. Deve-se enfatizar que o indivíduo padrão que recebe um salário mais elevado é o indivíduo que tem ensino superior completo. Em relação às pessoas com ensino superior completo, as pessoas com ensino médio completo têm salários médios cerca de $35 \%$ mais baixos; para aqueles com ensino superior incompleto, os salários médios são cerca de $23 \%$ mais baixos. Esse resultado já era esperado e é semelhante a estudos anteriores como os de Fields e Yoo (2000), Brighenti, Jacomossi e Silva (2015) e Hossain, Haque e Haque (2015). 
Esse resultado confirma o que é postulado pela teoria do capital humano, a qual prediz que investimentos com educação e qualificação resultam em melhores salários (MINCER, 1958; BECKER, 1964). No que diz respeito aos tipos de deficiências, física e auditiva foram destacadas. Pessoas com diferentes tipos de deficiência física tinham um salário médio de aproximadamente 17\% a menos (considerando o período estudado) que o indivíduo padrão (sem qualquer deficiência). Em relação aos que eram deficientes auditivos, no entanto, a média foi ainda menor, aproximadamente $20 \%$, considerado o indivíduo padrão.

Na maioria dos casos, os profissionais com algum tipo de deficiência recebem salários mais baixos. Esse resultado é confirmado pela ASID (2018), que observa que a maioria dos deficientes não está incluída no mercado de trabalho. Além disso, 46,4\% dos que se declararam deficientes e ocupam diferentes cargos recebem um salário mínimo. A Tabela 3 apresenta a variação da faixa etária por ano em relação ao indivíduo padrão (idade entre 30 e 39 anos).

Tabela 3

Faixa etária

\begin{tabular}{l|c|c|c|c|c|c|c}
\hline \multicolumn{1}{c|}{ Classificação } & 2009 & 2010 & 2011 & 2012 & 2013 & 2014 & 2015 \\
\hline $\begin{array}{l}\text { Salário (mensal) } \\
\text { Referência } * *\end{array}$ & 3.154 & 3.352 & 3.473 & 3.490 & 3.551 & 3.516 & 3.218 \\
\hline \multicolumn{7}{|c}{ Faixa etária } \\
\hline Aprendiz & $40,6 \%$ & $42,4 \%$ & $30,2 \%$ & $48,5 \%$ & $28,0 \%$ & $37,4 \%$ & $34,7 \%$ \\
\hline 15 a 17 anos & $63,2 \%$ & $61,8 \%$ & $62,1 \%$ & $60,9 \%$ & $63,7 \%$ & $64,1 \%$ & $81,8 \%$ \\
\hline 18 a 24 anos & $75,3 \%$ & $75,0 \%$ & $74,9 \%$ & $74,7 \%$ & $75,2 \%$ & $75,2 \%$ & $*$ \\
\hline 25 a 29 anos & $88,6 \%$ & $88,8 \%$ & $87,9 \%$ & $87,6 \%$ & $89,0 \%$ & $88,7 \%$ & $100,9 \%$ \\
\hline 40 a 49 anos & $107,0 \%$ & $107,0 \%$ & $106,8 \%$ & $164,0 \%$ & $107,7 \%$ & $106,8 \%$ & $118,8 \%$ \\
\hline 50 a 64 anos & $105,0 \%$ & $104,1 \%$ & $102,2 \%$ & $105,6 \%$ & $104,6 \%$ & $105,0 \%$ & $116,8 \%$ \\
\hline 65 anos ou & $83,5 \%$ & $82,9 \%$ & $86,6 \%$ & $*$ & $*$ & $79,6 \%$ & $109,4 \%$ \\
mais & & & & & & \\
\hline
\end{tabular}

Fonte: Dados da pesquisa.

* O modelo não apresentou significância estatística no nível de 5\%, para a variável.

* O padrão estabelecido pelo modelo: contador, homem, branco, idade entre 30 e 39 anos, ensino superior completo (graduado), sem deficiência, está pelo menos atuando no segundo emprego, trabalha em uma empresa com até quatro funcionários e que é da região Sudeste.

Observa-se que, entre as faixas etárias, quando a idade aumenta, o salário médio relativo sobe gradualmente comparativamente ao salário médio do indivíduo padrão (30 a 39 anos). As pessoas com idade entre 40 e 64 anos têm um salário médio relativo superior ao salário médio do indivíduo padrão (aproximadamente 18\%). Outro resultado que deve ser destacado aqui é que, para as pessoas com 65 anos ou mais, o salário médio é menor do que o salário médio do indivíduo padrão, isto é, tem um salário cerca de $12 \%$ menor do que o indivíduo padrão. Além disso, tem um salário $18 \%$ menor do que a faixa etária entre 50 e 64 anos de idade. Em outras palavras, quando a pessoa atinge a idade de 65 anos e o(a) profissional precisa continuar trabalhando, o salário médio diminui aproximadamente $18 \%$. A Tabela 4 apresenta a diferença salarial, segundo o tamanho da empresa do funcionário padrão, ou seja, com até quatro funcionários. 
Tabela 4

Tamanho da empresa

\begin{tabular}{l|c|c|c|c|c|c|c}
\hline \multicolumn{1}{c|}{ Classificação } & 2009 & 2010 & 2011 & 2012 & 2013 & 2014 & 2015 \\
\hline $\begin{array}{l}\text { Referência salarial } \\
\text { (mensal) } *\end{array}$ & 3.154 & 3.351 & 3.473 & 3.490 & 3.550 & 3.515 & 3.217 \\
\hline \multicolumn{7}{c}{ Tamanho da empresa } \\
\hline 5 a 9 funcionários & $*$ & $102,9 \%$ & $103,2 \%$ & $101,8 \%$ & $101,6 \%$ & $104,5 \%$ & $103,6 \%$ \\
\hline 10 a 19 funcionários & $108,5 \%$ & $110,3 \%$ & $109,6 \%$ & $108,3 \%$ & $107,3 \%$ & $109,3 \%$ & $109,0 \%$ \\
\hline 20 a 49 funcionários & $116,8 \%$ & $117,1 \%$ & $116,2 \%$ & $115,6 \%$ & $114,0 \%$ & $114,8 \%$ & $114,0 \%$ \\
\hline 50 a 99 funcionários & $124,6 \%$ & $122,4 \%$ & $123,2 \%$ & $122,3 \%$ & $119,0 \%$ & $120,6 \%$ & $120,7 \%$ \\
\hline 100 a 249 funcionários & $128,5 \%$ & $129,4 \%$ & $129,8 \%$ & $127,5 \%$ & $125,4 \%$ & $127,0 \%$ & $126,9 \%$ \\
\hline 250 a 499 funcionários & $133,7 \%$ & $135,9 \%$ & $133,1 \%$ & $133,3 \%$ & $128,9 \%$ & $129,9 \%$ & $131,3 \%$ \\
\hline 500 a 999 funcionários & $134,5 \%$ & $135,5 \%$ & $132,1 \%$ & $135,6 \%$ & $135,6 \%$ & $132,2 \%$ & $125,1 \%$ \\
\hline 1.000 ou + funcionários & $146,9 \%$ & $149,5 \%$ & $144,5 \%$ & $141,6 \%$ & $137,0 \%$ & $138,2 \%$ & $132,0 \%$ \\
\hline
\end{tabular}

Fonte: Dados de pesquisa.

* O modelo não apresentou significância estatística no nível de 5\%, para a variável.

* O padrão estabelecido pelo modelo: contador, homem, branco, idade entre 30 e 39 anos, ensino superior completo (graduado), sem deficiência, está pelo menos atuando no segundo emprego, trabalha em uma empresa com até quatro funcionários e que é da região Sudeste.

O indivíduo padrão é a pessoa que trabalha em empresas com até quatro funcionários, ou seja, atua em empresas de pequeno porte. Percebe-se que, em geral, quanto maior o tamanho da empresa (segundo o número de funcionários), maior o salário dos funcionários da área contábil. Isso é recorrente em todos os anos analisados, uma vez que a variação ultrapassa 100\%, ou seja, o salário desses profissionais é maior do que os salários daqueles que trabalham em empresas com até quatro funcionários.

Vale ressaltar que, em 2015, houve uma pequena redução na variação dos salários para todas as faixas de número de empregados. Os resultados corroboram com os achados de Fields e Yoo (2000), Brighenti, Jacomossi e Silva (2015) e Silva, Dal Magro e Silva (2016), que identificaram que o tamanho da empresa afeta os salários. Por fim, no que diz respeito às regiões brasileiras, na Tabela 5 tem-se como indivíduo padrão um profissional da região Sudeste.

Tabela 5

Região geográfica

\begin{tabular}{l|c|c|c|c|c|c|c}
\hline Classificação & 2009 & 2010 & 2011 & 2012 & 2013 & 2014 & 2015 \\
\hline $\begin{array}{l}\text { Salário } \\
\text { (mensal) ** }\end{array}$ & 3.154 & 3.351 & 3.473 & 3.490 & 3.550 & 3.515 & 3.217 \\
\hline \multicolumn{7}{c}{ Região } \\
\hline Norte & $82,2 \%$ & $89,8 \%$ & $79,5 \%$ & $78,0 \%$ & $78,1 \%$ & $80,3 \%$ & $80,3 \%$ \\
\hline Nordeste & $69,9 \%$ & $71,8 \%$ & $69,6 \%$ & $71,5 \%$ & $72,2 \%$ & $72,4 \%$ & $74,9 \%$ \\
\hline Sul & $87,3 \%$ & $86,1 \%$ & $86,4 \%$ & $88,5 \%$ & $89,0 \%$ & $89,6 \%$ & $91,6 \%$ \\
\hline Centro-Oeste & $84,6 \%$ & $81,2 \%$ & $83,3 \%$ & $85,2 \%$ & $84,8 \%$ & $85,7 \%$ & $88,0 \%$ \\
\hline
\end{tabular}

Fonte: Dados de pesquisa.

* O modelo não apresentou significância estatística no nível de 5\%, para a variável.

* O padrão estabelecido pelo modelo: contador, homem, branco, idade entre 30 e 39 anos, ensino superior completo (graduado), sem deficiência, que está pelo menos atuando no segundo emprego, que trabalha em uma empresa com até quatro funcionários e que é da região Sudeste. 
Os funcionários da área contábil localizados na região Sul são os que têm a menor diferença salarial comparativamente aos que trabalham na região Sudeste (indivíduo padrão); exceto em 2010, em que a menor diferença foi observada para a região Norte $(89,8 \%)$. Portanto, há uma discriminação salarial entre as regiões brasileiras, em favor da região Sul (maior região comercial e industrial do país). A região Sul (segunda região brasileira em questão econômica) e a região Centro-Oeste são aquelas que estão mais próximas dos salários pagos no Sudeste. Por outro lado, os piores salários são os da região Nordeste. A região Nordeste também foi identificada como a que paga menos aos profissionais na pesquisa de Campante, Crespo e Leite (2004).

De acordo com os resultados de Campante, Crespo e Leite (2004), o salário no Nordeste está ligado ao fato de que os indivíduos pobres se classificam como negros ou mulatos, aumentando a diferença salarial na região. No entanto, os resultados desta pesquisa são diferentes dos obtidos por esses autores, que analisaram o problema intrarregião. Eles afirmam que a região Sudeste excede a média nacional de discriminação salarial. Fields e Yoo (2000), Agbodji, Batana e Ouedraogo (2015) e Castellano Manna e Punzo (2016) concluíram que em muitos países há uma diferença salarial em Estados e regiões, o que corrobora com os resultados encontrados nesta pesquisa.

A partir desses resultados, pode-se confirmar o que a teoria da segmentação propõe. Ou seja, os funcionários podem receber salários diferentes, mesmo que sejam igualmente produtivos. Nesse caso, a segmentação ocorre justamente quando indivíduos com características semelhantes recebem diferentes salários (SOUZA, 1978).

\section{CONCLUSÕES}

Esta pesquisa teve como objetivo descrever os fatores determinantes das diferenças salariais entre os profissionais da contabilidade no Brasil de 2009 a 2015. Os profissionais contábeis analisados neste estudo foram auxiliares contábeis, contadores e auditores. Estimou-se, por meio de múltiplas regressões com variáveis binárias, os fatores que afetam o salário, ou seja: ocupação, gênero, raça, idade, escolaridade, deficiência, tamanho da empresa, movimentação de funcionários (tipo) e regiões.

A pesquisa foi realizada analisando os funcionários, pressupondo que a idade das empresas não interfere nos resultados. É relevante mencionar que o Brasil é interessante para este estudo, pois, além de ser o maior país da América Latina, posiciona-se entre os países com maior desigualdade salarial do mundo. Além disso, os profissionais de contabilidade fazem parte de um setor importante para as empresas, bem como são um grupo profissional de destaque.

A partir dos resultados, pode-se concluir que, em relação ao problema e ao objetivo da pesquisa, foi escolhido um indivíduo padrão, que representa as características mais frequentes de um profissional contábil. As características são: homem, contador, funcionário de uma empresa com até quatro funcionários, graduado (ensino superior completo), com idade entre 30 e 39 anos, branco, não têm nenhum tipo de deficiência, está (pelo menos) em seu segundo emprego e atua na região Sudeste do Brasil.

Para que um profissional da área contábil possa obter salário médio superior ao padrão estimado, é necessário mudar pelo menos uma dessas características do indivíduo padrão. É preciso que o contador trabalhe em uma grande empresa, especialmente com mais de mil funcionários. Outra possibilidade de obter salários mais elevados é quando o funcionário (contador) está na faixa etária entre 40 e 49 anos de idade. Portanto, os profissionais que apresentam as características do indivíduo padrão, ajustados a essas últimas mudanças, têm os salários majorados (com base em dados). Isso endossa o que está exposto na teoria do capital humano e na teoria da segmentação.

Com base nos resultados, é possível avaliar algumas questões e propor ações para reduzir a lacuna salarial entre as empresas e entre os profissionais. Isso contribui para a criação de uma base salarial em diferentes níveis de desempenho. Essa ação é importante para a área contábil, pois proporciona maior garantia e incentivo à profissão no cenário nacional (JEACLE, 2011). Como já afirmado por Campante, Crespo e Leite (2004) e Hossain, Haque e Haque (2015), políticas públicas devem ser consideradas para reduzir a desigualdade social e salarial em todo o país. Sobre a desigualdade entre homens e mulheres, Jayachandran (2015) ressalta que, em qualquer país, desenvolvido ou não, os políticos têm muitas ferramentas para acelerar o processo de redução da desigualdade. 
A pesquisa contribui para algumas questões que precisam de atenção, pois representam discriminação, como os deficientes, cuja desigualdade salarial é elevada. Ao mesmo tempo, as mulheres recebem salários mais baixos e apresentam dificuldade para ocupar cargos superiores. A região do país e a raça também são fatores que tornam o cenário de desigualdade relevante, e, portanto, algumas ações de entidades públicas ou privadas são necessárias para melhorar essa situação. Desse modo, sem dúvida, saber os fatores determinantes é importante para revisar e planejar políticas públicas e aumentar a conscientização entre as empresas. Isso para reduzir a desigualdade salarial, que afeta um número considerável de trabalhadores em todo o mundo.

As limitações do estudo dizem respeito aos dados, por não apresentarem informações sobre o tempo de experiência dos profissionais, por exemplo. Para tanto, sugere-se expandir essa pesquisa para analisar a experiência dos funcionários e verificar se a diferença salarial pode ser explicada por esse fator. Outra recomendação seria analisar os próximos anos com dados disponíveis, para observar se haverá redução da desigualdade em relação aos fatores. Outra proposta de estudos futuros é a análise do impacto da crise econômica na profissão contábil e no gênero dos profissionais. Isso porque houve uma redução salarial significativa, especialmente em 2014/2015, e a crise pode ser um fator explicativo desse fenômeno. 


\section{REFERÊNCIAS}

AGBODJI, A. E.; BATANA, Y. M.; OUEDRAOGO, D. Gender inequality in multidimensional welfare deprivation in West Africa: the case of Burkina Faso and Togo. International Journal of Social Economics, v. 42, n. 11, p. 980-1004, 2015.

AÇÃO SOCIAL PARA IGUALDADE DAS DIFERENÇAS - ASID. Censo do IBGE 2010 Revela Realidade da Pessoa com Deficiência no Brasil. Disponível em: <http://asidbrasil.org.br/censo-do-ibge-2010-revelarealidade-da-pessoa-com-deficiencia-no-brasil/>. Acesso em: 24 maio 2016.

BAUDER, H. Culture in the labor market: segmentation theory and perspectives of place. Progress in human geography, v. 25, n. 1, p. 37-52, 2001.

BECKER, G. S. Human capital a theoretical and empirical analysis, with special reference to education. New York: Columbia University Press, 1964.

BRIGHENTI, J.; JACOMOSSI, F.; SILVA, M. Z. da. Desigualdades de sexo na atuação de Contadores e Auditores no mercado de trabalho catarinense. Enfoque: Reflexão Contábil, v. 34, n. 2, p. 109-122, 2015.

BRUNO, A. S. Analyser les écarts de salaires à l'aide des modèles de régression. Vertus et limites d'une méthode. Le cas des migrants de Tunisie en région parisienne après 1956. Histoire \& Mesure, v. 25, n. XXV-2, p. 121-156, 2010.

CAMPANTE, F. R.; CRESPO, A. R.V.; LEITE, P. Desigualdade salarial entre raças no mercado de trabalho urbano brasileiro: aspectos regionais. Revista Brasileira de Economia, v. 58, n. 2, p. 185-210, 2004.

CASTELLANO, R.; MANNA, R.; PUNZO, G. Income inequality between overlapping and stratification: a longitudinal analysis of personal earnings in France and Italy. International Review of Applied Economics, v. 30, n. 5, p. 567-590, 2016.

CATHO. Queda no salário de admissão se intensifica em junho e tem segundo pior resultado em 11 anos. 2016. Disponível em: <http:// www.catho.com.br/institucional/2015/08/queda-no-salario-deadmissao-se-intensifica-em-junho-e-tem-segundo-pior-resultadoem-11-anos/>. Acesso em: 24 maio 2018.

DARITY, W. A. Labor economics: problems in analysing labor markets. Springer Science \& Business Media, 1993.

DIBB, S.; SIMKIN, L. Bridging the segmentation theory/practice divide. Journal of Marketing Management, v. 25, n. 3-4, p. 219-225, 2009.

DREHER, A.; GEHRING, K.; KLASEN, S. Gesture politics or real commitment? Gender inequality and the allocation of aid. World Development, v. 70, p. 464-480, 2015.

DUNLOP, J. T. The Theory of Wage Determination. New York: MacMillan \& Co Limited, 1957.

FIELDS, G. S.; YOO, G. Falling labor income inequality in Korea's economic growth: Patterns and underlying causes. Review of Income and Wealth, v. 46, n. 2, p. 139-159, 2000.

FIELDS, G. S. Accounting for income inequality and its change: A new method, with application to the distribution of earnings in the United States. Research in Labor Economics, v. 22, n. 3, p. 1-38, 2003.
FOX, B. J.; FOX, J. Women in the labour market, 1931-81: Exclusion and competition. Canadian Review of Sociology, v. 23, n. 1, p. 1-21, 1986.

FOX, M. F. Sex, salary, and achievement: Reward-dualism in academia. Sociology of Education, v. 54, n. 2, p. 71-84, 1981.

GERHART, B.; MILKOVICH, G. T. Organizational differences in managerial compensation and financial performance. Academy of Management Journal, v. 33, n. 4, p. 663-691, 1990.

GUJARATI, D. N.; PORTER, D. C. Econometria Básica. 5 ed. Porto Alegre: AMGH Editora, 2011.

HANUSHEK, E. A. Economic growth in developing countries: The role of human capital. Economics of Education Review, v. 37, p. 204-212, 2013.

HAYNES, K. Accounting as gendering and gendered: A review of 25 years of critical accounting research on gender. Critical Perspectives on Accounting, v. 43, p. 110-124, 2017.

HAYNES, K. Moving the gender agenda or stirring chicken's entrails? Where next for feminist methodologies in accounting?. Accounting, Auditing \& Accountability Journal, v. 21, n. 4, p. 539-555, 2008.

HELAL, D. H. Flexibilização organizacional e empregabilidade individual: proposição de um modelo explicativo. Cadernos EBAPE.BR, Rio de Janeiro, v. 3, n. 1, p. 1-15, 2005.

HOSSAIN, K. A.; HAQUE, S. M.; HAQUE, A. E. An Analysis of the Determinants of Wage and Salary Differentials in Bangladesh. South Asia Economic Journal, v. 16, n. 2, p. 295-308, 2015.

INSTITUTO BRASILEIRO DE GEOGRAFIA E ESTATÍSTICA - IBGE. PNAD 2015: rendimentos têm queda e desigualdade mantém trajetória de redução. Disponível em: <http://saladeimprensa.ibge.gov.br/noticias. html?view=noticia $>$. Acesso em: 24 abr. 2018.

IGBARIA, M.; CHIDAMBARAM, L. The impact of gender on career success of information systems professionals: A human-capital perspective. Information Technology \& People, v. 10, n. 1, p. 63-86, 1997.

JAYACHANDRAN, $\mathrm{S}$. The roots of gender inequality in developing countries. Economics, v. 7, n. 1, p. 63-88, 2015.

JEACLE, I. A practice of her own: Female career success beyond the accounting firm. Critical Perspectives on Accounting, v. 22, n. 3, p. 288-303, 2011.

KONRAD, A. M.; PFEFFER, J. Do you get what you deserve? Factors affecting the relationship between productivity and pay. Administrative Science Quarterly, v. 35, n. 2, p. 258-285, 1990.

MINCER, J. Investment in human capital and personal income distribution. Journal of Political Economy, v. 66, n. 4, p. 281-302, 1958.

MINCER, J. Schooling, experience, and earnings. New York: NBER, 1974.

MINCER, J. The distribution of labor incomes: A survey with special reference to the human capital approach. Journal of Economic Literature, v. 8, n. 1, p. 1-26, 1970.

MORRISON, P. S. Segmentation theory applied to local, regional and spatial labour markets. Progress in Human Geography, v. 14, n. 4, p. 488-528, 1990. 
MINISTÉRIO DO TRABALHO - MTE. Cadastro Geral de Empregados e Desempregados (CAGED). Disponível em: <http://trabalho.gov. br/trabalhador-caged>. Acesso em: 02 maio 2018.

NEVES, J. A.; FERNANDES, D. C. Estrutura ocupacional, autoridade gerencial e determinação de salários em organizações fordistas: o caso da indústria de transformações no Brasil. RAC - Revista de Administração Contemporânea, v. 6, n. 1, p. 127-140, jan./abr. 2002.

ORGANIZATION FOR ECONOMIC CO-OPERATION AND DEVELOPMENT - OECD. Income inequality (indicator). Disponível em: <https://data. oecd.org/inequality/income-inequality.htm>. Acesso em: 20 jun. 2018.

ORGANIZAÇÃO DAS NAÇÕES UNIDAS - ONU. América Latina e Caribe é região mais desigual do mundo, revela comissão da ONU. Disponível em: <https://nacoesunidas.org/ america-latina-e-caribe-e-regiao-mais-desigual-do-mundo-revelacomissao-da-onu/>. Acesso em: 20 jun. 2018.

PFEFFER, J.; LANGTON, N. Wage inequality and the organization of work: The case of academic departments. Administrative Science Quarterly, v. 33, n. 4, p. 588-606, 1988.

SCHULTZ, T. W. Investment in human capital. American Economic Review, v. 51, n. 1, p. 1-17, 1961.

SILVA, J. C.; DAL MAGRO, C. B.; SILVA, M. Z. da. Gender inequality in accounting profession from the perspective of the glass ceiling. RACE - Revista de Administração, Contabilidade e Economia, v. 15, n. 2, p. 447-474, 2016

SOUZA, M. C. C. D. Mercado de trabalho: abordagens duais. Revista de Administração de Empresas, v. 18, n. 1, p. 59-69, 1978.

Mara Vogt

ORCID: https://orcid.org/0000-0002-3951-4637

Doutora em Contabilidade e Administração pela Universidade Regional de Blumenau (FURB), Blumenau - SC, Brasil. E-mail: maravogtcco@gmail.com

Edmery Tavares Barbosa

ORCID: https://orcid.org/0000-0001-6000-2831

Professora Adjunta na Universidade Federal da Paraíba (UFPB); Doutoranda em Contabilidade na Faculté de Sciences d'Administration da Université Laval- Quèbec-Canadá; Mestre em Contabilidade pela Universidade Regional de Blumenau (FURB); Master Recherche en Comptabilité, Management et Audit- Université Paris Dauphine - Paris, França. E-mail: edmery.tavares-barbosa.1@ulaval.ca

Marcia Zanievicz da Silva

ORCID: http://orcid.org/0000-0003-1229-7705

Doutora em Contabilidade e Administração pela Universidade Regional de Blumenau (FURB); Professora do Programa de Pós-Graduação em Ciências Contábeis da Universidade de Blumenau (FURB), Blumenau - SC, Brasil. E-mail: mzsilva@furb.br

Arno Paulo Schmitz

ORCID: http://orcid.org/0000-0001-6924-9611

Doutor em Desenvolvimento Econômico pela Universidade Federal do Paraná (UFPR); Professor adjunto no Setor de Educação Profissional e Tecnológica da Universidade Federal do Paraná (UFPR), Curitiba - PR, Brasil. E-mail: arno@ufpr.br 